\title{
A História do Turismo: epítome das mudanças
}

\section{The History of Tourism: epitome of changes}

\author{
Sérgio Kaoru Nakashima (NAKASHIMA, S. K.) ${ }^{*}$ e \\ Maria del Carmen Matilde Huertas Calvente (CALVENTE, M. del C. M. H.) ${ }^{* *}$
}

RESUMO - O texto deste artigo foi produzido com o objetivo de, através de revisão bibliográfica, identificar e compreender os principais aspectos dos processos sociais históricos que culminaram na importância contemporânea da atividade turística. Por ser um exercício de síntese, se privilegiou as informações relativas ao mundo ocidental, na passagem do turismo ainda como uma atividade realizada especialmente por pequenos grupos que podiam realizar deslocamentos espaciais até hoje, quando a viagem passa a ser um desejado objeto de consumo e praticada pela grande maioria das pessoas. Para isso, mudanças econômicas, sociais e tecnológicas tiveram que ocorrer e são abordadas no contexto da história do turismo. Por exemplo, as formas de hospedagem e os meios de deslocamento passaram por significativas transformações, com mudanças ligadas a determinados momentos na história da humanidade, transformações que passaram a permitir o deslocamento de imensa massa de turistas através do planeta.

Palavras-chave: Turismo; Processo Histórico; Mudanças.

ABSTRACT - The text of this article was produced with the goal, through literature review, identify and understand the main aspects of the historical processes that culminated in the importance of tourist activity in the present day. For being an exercise in synthesis, privileged information relating to the Western world, in the passage of the tourism as an activity performed especially by small groups that could perform spatial displacements to the moment in which the journey becomes a desired object of consumption and practiced by the vast majority of people. To this, economic, social and technological changes have to occur and are addressed in the context of the history of tourism. For example, the forms of hosting and the offset passed through significant transformations, with changes linked to certain moments in the history of mankind, transformations that allow today the offset of immense mass of tourists through the planet.

Key words: Tourism; Historical Process; Changes.

\footnotetext{
* Formação: Graduação em Geografia pela Universidade Estadual de Londrina (UEL). Discente do Mestrado em Geografia da Universidade Estadual de Londrina (UEL). Atividade profissional: Professor de Rede Estadual de Ensino do Paraná. Endereço físico para correspondência: Rodovia Celso Garcia Cid - PR 445 Km 380, s./n. - Campus Universitário. CEP: 86057-970 - Londrina - Paraná/PR - Brasil. Email: sergiokn@hotmail.com

** Formação: Graduação, Mestrado e Doutorado em Geografia pela Universidade de São Paulo (USP). Atividade profissional: Docente da Universidade Estadual de Londrina (UEL). Endereço físico para correspondência: Rodovia Celso Garcia Cid - PR 445 Km 380, s./n. - Campus Universitário. CEP: 86057970 - Londrina - Paraná/PR - Brasil. E-mail: calvente@uel.br
} 


\section{INTRODUÇÃO}

As discussões a respeito do turismo e sua importância como prática social têm ocorrido com frequência em várias ciências, em particular nas Ciências Humanas. Por exemplo, discute-se: $\mathrm{O}$ que é o turismo, como conceito que pode ser aceito cientificamente? Quando começou? Quais são os seus maiores impactos (negativos e positivos)? Como pode ser estudado? De acordo com posturas epistemológicas diversas, as respostas também serão diferenciadas para todas estas questões, e muito frequentemente as respostas apenas indicarão a necessidade de aprofundar os estudos a respeito.

Este artigo é o resultado de busca específica, a de compreender os aspectos fundamentais dos processos históricos, de mudanças sociais e técnicas, que transformaram a atividade turística em uma das principais atividades econômicas do mundo contemporâneo. Utilizando como método a revisão bibliográfica, se fez um esforço de síntese ou um epítome dos resultados obtidos, que pode ser útil para uma compreensão inicial da história do turismo.

\section{A HISTÓRIA DO TURISMO}

A abordagem sobre a origem do turismo não é única, principalmente porque o recorte temporal nas obras dos autores é bastante diverso. Na pesquisa realizada, Amaral Júnior (2008) e Fratucci (2008) são os autores que mais retrocedem no tempo em suas obras abordando as origens do turismo, ainda no Antigo Egito e nos impérios Grego e Romano, enquanto que Pires (2002) inicia relatando a atividade do turismo no século XII, na parte final da Idade Média e Trigo (1998) aborda em sua obra o turismo moderno, a partir do século XIX.

[...] há 5.000 anos, os Egípcios organizaram e conduziram as primeiras cruzadas. Provavelmente, a primeira viagem com propósitos de paz e turismo tenha sido feita pela Rainha Hatshepsut indo para as terras de Punt, ao norte da África, em 1480 a.C. Registros desta viagem estão gravadas nas paredes do Templo de Deit El Bahari em Luxor. Mas foi o grego Pausanias quem escreveu, entre 160 e 180 d.C., o "Guidebook of Greece" que talvez seja o único registro sobre um guia de viagens remanescente daquela época. (AMARAL JUNIOR, 2008, p. 34-35). 
De acordo com Fratucci (2008, p. 29), “[...] os deslocamentos espaciais merecem ser destacados, pois o homem nunca deixou de viajar, de percorrer territórios, conhecidos ou desconhecidos". Esses deslocamentos existiram desde o princípio da história da humanidade, já que os homens não possuíam moradia fixa.

Assunção (2012) considera que os motivos que levam o homem a se deslocar são vários, levando em consideração a trajetória da história da humanidade. Isso permite experiências diferenciadas, surpreendentes, positivas ou negativas. Se deslocar para os diversos lugares possibilitou ao homem ampliar seus conhecimentos em relação ao mundo e com isso compreendê-lo melhor.

Conforme Amaral Junior (2012), logo após as pirâmides do Antigo Egito serem construídas por volta de 2700 a.C já atraíam visitantes por motivos religiosos ou simplesmente por curiosidade. Em 1800 a.C. os Egípcios já faziam deslocamento para participar de eventos festivos. Esses deslocamentos por pessoas eram feitos em caminhos simples e originaram as primeiras estradas entre as cidades da Mesopotâmia.

\begin{abstract}
Depois vieram as estradas da ilha de Creta (de 2000 a 1500 a.C.), as da Grécia (de 1600 a 1200 a.C), posteriormente as estradas uniriam cidades maiores. Alexandre, o Grande, fundou a mais desenvolvida para a época, em 326 a.C na Índia. Já na Pérsia em 500/400 a.C., as cidades e províncias eram conectadas com a capital Susa. Em 150 a.C., foi a vez dos Romanos inaugurarem a sua estrada, e em dois a três séculos depois, contavam com uma malha de estradas que somavam mais de $80.000 \mathrm{~km}$ em todo o território compreendido pelo seu Império [...] por terra e também por mar - por rio, tem-se que os Egípcios navegaram pelo Nilo em pequenas embarcações, em 2000 a.C., os Fenícios se aventuraram pelo Mar Mediterrâneo indo até a costa ocidental da África e Açores. (AMARAL JUNIOR, 2008, p. 35).
\end{abstract}

Assim, o autor informa que, além da utilização das estradas, os deslocamentos por vias aquáticas foram importantes para esses povos, principalmente por motivos mercantis. As razões de sobrevivência explicam porque historicamente as grandes civilizações mundiais ao longo da história se desenvolveram às margens do litoral ou de um rio importante. As primeiras olimpíadas, surgidas na Grécia Antiga, foram outra causa de deslocamentos expressivos. Eram consideradas grandes eventos para este poderoso império, duravam dias e atraíam milhares de pessoas. Paralelo a isso também surgiram os vendedores de alimentos, de vinho e de "suvenir".

Estas regiões [da Grécia Antiga] recebiam, além de filósofos e poetas, comerciantes, músicos, atores, bailarinos e atletas. Mas não somente havia viagens motivadas pela cultura, negócio ou esporte, os deslocamentos de 
grande número de pessoas por questões religiosas também eram observadas em todo o mundo helênico, especialmente Delfos, onde se situava o oráculo sagrado de Apolo. (AMARAL JUNIOR, 2008, p. 36).

O relevo montanhoso da Grécia não impediu os deslocamentos por motivos religiosos nesse império, conforme Assunção (2012). Esclarece que essas estradas também foram utilizadas para transportar mercadorias utilizando animais. Mas sem dúvida alguma as rotas marítimas foram mais importantes que as terrestres para o comércio e para a locomoção de pessoas, como já abordado anteriormente.

Além disso, houve “[...] também, na época, fluxos gerados por razões voltadas a saúde, além das viagens em busca das águas minerais" (AMARAL JUNIOR, 2008, p. 36-37). Na obra de Assunção (2012) é destacado que a possibilidade dessa prática estava ligada aos aspectos socioeconômicos de camadas da população e que era restrito somente às famílias ricas, formadas por uma minoria. Esclarece que a maior parte desta população não tinha posses e consequentemente também não tinham tempo disponível e nem condições de se deslocar para se divertir.

Fratucci (2008) também informa que no Império Romano houve deslocamento de pessoas em busca de tratamentos de saúde nas termas, e pelos espetáculos circenses e lutas. Esses eventos eram uma forma de entretenimento do público. $\mathrm{O}$ autor defende que provavelmente as viagens por motivos de lazer tiveram suas origens entre os antigos romanos.

\footnotetext{
Eles demonstravam, inclusive, preocupação com alguns elementos básicos para a concretização das viagens de lazer e descanso: estradas calçadas, sistema de comunicação e segurança e tinham consciência da existência de períodos de tempo livre [...] para alguns súditos do Império, que precisavam ser "preenchidos" com atividades saudáveis e prazerosas. (FRATUCCI, 2008, p. 31).
}

Escreve Assunção (2012) que, para um império tão vasto como o de Roma era necessária grande mobilidade, para controle ou proteção. Os deslocamentos eram constantes em partes do continente europeu, asiático e africano, utilizando o Mar Mediterrâneo. Os antigos romanos o chamavam de Mare Nostrun ("Mar Nosso" em latim). Neste período da história, o litoral do Mediterrâneo também era muito frequentado por pessoas em busca de repouso e fuga da trivialidade do dia a dia. Outras 
pessoas preferiam se refugiar no campo, principalmente no verão. A valorização do litoral, portanto, não é algo inédito da Idade Contemporânea.

Bursztyn (2005) aborda outro marco na origem de viagens, as peregrinações. Já nos primeiros séculos do Cristianismo um grande número de pessoas se deslocava a Roma, a Jerusalém e posteriormente, já no final do primeiro milênio, a Santiago de Compostela. Os islâmicos viajavam à Meca, além de outras peregrinações no continente asiático realizadas pelos hindus e budistas. Segundo os princípios da religião Islâmica, cada seguidor deve fazer pelo menos uma vez na vida uma peregrinação à Meca, a cidade sagrada. Além da região do Oriente Médio, com a propagação do Islamismo, os deslocamentos de fiéis se estenderam também do Norte do continente africano e da Península Ibérica.

"Durante a Idade Média, houve uma redução acentuada nos deslocamentos de pessoas na Europa em virtude, principalmente, da fragmentação do território em feudos" (BURSZTYN, 2005, p. 8). Para o autor, esse processo lento, mas não estático, foi uma característica marcante desse período da história europeia, que durou pelo menos um milênio.

Conforme informações contidas na obra de Fratucci (2008, p. 32), nesse período a atividade das “[...] Cruzadas fez ressurgir, no território europeu e no Oriente Médio, as viagens, contribuindo para a revitalização do comércio e para o surgimento da atividade comercial da hospedagem".

Explica Fratucci (2008) que as Cruzadas, além do princípio religioso e militar, também foram de interesse político e econômico. Além de pessoas e mercadorias, também circularam muitas ideias entre esses dois continentes, mudando a forma de pensar do Ocidente. No início os viajantes eram recebidos em mosteiros e por moradores nos caminhos das Cruzadas. Segundo os princípios cristãos, os serviços prestados deveriam ser ausentes de interesses econômicos e atos de caridade. A partir do século IV surgiram construções especialmente para hospedagem, sendo que a mais conhecida se localizava nos Alpes da França, no século X. Com o acréscimo do número de viajantes, as dificuldades e os custos aumentaram proporcionalmente. Os mosteiros e moradores já não conseguiam mais atender a todos. Assim as tabernas também passaram a oferecer os serviços de hospedagem, mas de forma remunerada. Essa 
atividade passou a ser rentável e de crescimento, principalmente na Península Itálica e nos Alpes da Suíça.

Pires (2002, p. 2) inicia seu recorte histórico sobre as origens do turismo precisamente no ano de 1298, nos séculos finais da Idade Média em que “[...] proprietários das principais pousadas de Florença reuniram-se [...] com o propósito de transformar a hospedagem - até então quase sempre uma ação de caridade - numa atividade comercial".

Em sua tese Fratucci (2008, p. 32) afirma que já em 1290 o número de pousadas em Florença com licenças chegava a 86. "Seguindo o exemplo de Florença, Roma e Veneza também regulamentaram o negócio de hospedagem na mesma época”. O desejo de conhecer algo novo ou de chegar a lugares desconhecidos foi incentivo ao homem de espírito aventureiro e desafiador para descobrir outras terras e diferentes formas de culturas e aspectos físicos nas diversas partes do mundo.

\begin{abstract}
A curiosidade e o instinto sempre incitaram a busca por outros lugares diferentes, próximos ou distantes. A necessidade de saber o que existe para além de uma simples montanha ou do outro lado de uma grande massa de água, parece levar o homem a arriscar-se, afastando-se do seu habitat natural para descobrir novos lugares. (FRATUCCI, 2008, p. 29).
\end{abstract}

"Essa curiosidade aliada a fortes interesses comerciais fez com que, anos mais tarde, algumas nações europeias se lançassem ao mar rumo às riquezas do novo mundo" (BURSZTYN, 2005, p. 8). Isso associado também a outros fatores importantes:

\begin{abstract}
Os avanços técnicos no decorrer do século XIII a XV, tais como a bússola, o astrolábio, a vela latina, o timão na proa e novos tipos de navios permitiram que as navegações ganhassem uma nova dimensão. Esse movimento foi acompanhado pelas representações que descreviam portos e rotas náuticas conhecidas. A intensificação da circulação e da observação conduziu ao desenvolvimento tecnológico que possibilitou novos avanços. $\mathrm{O}$ uso dos astros passou a ser um ponto fundamental na navegação. A estrela polar (Draconis) servia como uma referência e, se não fosse possível visualizá-la, os navegadores procuravam outra estrela. Com a introdução da agulha magnética na navegação e seu uso, mais intenso a partir do século $\mathrm{V}$ a.C., a localização da embarcação poderia ser feita com maior precisão. (ASSUNÇÃO, 2012, p. 10).
\end{abstract}

$\mathrm{Na}$ abordagem de Assunção (2012) esse avanço técnico foi uma verdadeira revolução na época para a navegação das potências ocidentais do continente europeu, o 
que permitiu chegar até ao continente americano e também continuar as conquistas e exploração em outros locais da África e da Ásia.

Para Amaral Junior (2008), com o início das Grandes Navegações, notadamente no período do século XV ao XVIII, passaram a serem consideráveis as viagens marítimas intercontinentais, de longa distância. O autor discorre que, além do principal propósito das viagens (sem dúvida foram os interesses econômicos) a busca também foi pelo saber de outros povos e o de conhecer novos lugares. Comenta que nesse significativo intervalo de tempo Marco Pólo fez sua viagem à China e Cristóvão Colombo e Pedro Álvares Cabral ao continente americano e que este grande marco na História mundial está, de certa forma, associado com o atual turismo de aventura e riscos. Entretanto, na época, essas jornadas muitas vezes duravam meses ou até mesmo anos e é claro que trouxeram importantes consequências e alterações no cenário mundial.

\begin{abstract}
As percepções das distâncias e dos espaços se alteraram com as descobertas marítimas. O avanço pelo Oceano Atlântico e, posteriormente, pelo Índico e Pacífico, fez que os mercados se ampliassem, ao mesmo tempo em que revolucionavam os conceitos geográficos. As viagens permitiram novas ligações e trocas de conhecimentos. As contribuições para o saber eram sensivelmente ampliadas, tanto na economia como na organização social e na cultura. A América fornecia condições ideais para o enriquecimento. A circulação de pessoas se intensificou. Homens cruzavam o Oceano Atlântico em busca de riqueza, a fim de acumular recursos e voltarem para a Europa. (ASSUNÇÃO, 2012, p. 28).
\end{abstract}

O mesmo autor comenta que os fatos ocorridos e contados por pessoas que se aventuravam no Novo Mundo não tardaram a se espalhar por diversas partes do continente europeu, servindo de inspiração para artistas e escritores, que retrataram isso em suas obras, mesmo que em diversas vezes exageradas ou idealizadas.

No decorrer dos séculos XV e XVI, a literatura de viagens conquistou maior ressonância com as grandes viagens marítimas. Os registros dos navegadores descreveram com pormenores as riquezas da natureza, a sociedade, as tradições e costumes de sociedades desconhecidas. Cada avanço era uma aventura com outros povos. Um universo totalmente novo a ser comunicado. As descobertas marítimas alteraram os ritmos da vida cotidiana dos indivíduos dos séculos XV e XVI. A viagem, pelos mares, exigia uma reunião de interesses econômicos, políticos e, sem dúvida, culturais. (ASSUNÇÃO, 2012, p. 28). 
Outros elementos do contínuo processo histórico são trazidos por Fratucci (2008). No século XVII, ingleses funcionários do governo, negociantes e estudantes viajavam para vários países da Europa, cada qual com seus objetivos, mas frequentemente estas jornadas duravam anos. A aristocracia anglo-saxônica, detentora do poder no país, considerava que:

[...] a educação dos filhos deveria ser coroada com uma viagem por todos os lugares cultos e importantes da Europa. [...] Inicialmente, a denominada grand tour clássica tinha uma duração média de três anos e seu itinerário incluía uma demorada estada na França, especialmente em Paris, seguida de visitas a Genova, Florença, Roma e Veneza. O retorno era feito através da Alemanha e dos Países Baixos, via Suíça. Com as descobertas de novas terras, os mais abastados passaram a incluir nas suas grand tours, viagem às Américas, às Índias Orientais, ao Extremo Oriente, ao Brasil, mais especificamente ao Rio de Janeiro e ao sul da África. (FRATUCCI, 2008, p. $33)$.

Informa Assunção (2012, p. 16) que, para os grand tours realizados dentro do continente europeu, os viajantes davam preferência, sobretudo, à Itália. Esta escolha tinha uma série de motivos como “[...] o clima mediterrâneo, as universidades renomadas, as antiguidades dos romanos e do Renascimento e as ideias em voga. Estes eram elementos que atraíam aqueles que valorizavam a cultura e aspiravam ao conhecimento". Ressalta que essas viagens eram práticas acessíveis apenas a um pequeno grupo da camada social britânica e tinham várias finalidades, considerando que essas experiências eram importantes para a formação do indivíduo, para os diversos desafios ao longo da vida e no trabalho.

\footnotetext{
A viagem estimulava no viajante a coragem, a necessidade de atitude e o espírito de iniciativa. Além disso, o deslocamento exigia que o jovem tivesse não só atitude de comando, como também capacidade para tomar decisões rápidas. Esses elementos acrescidos dos conhecimentos de outras culturas, bons usos de convívio social e do domínio de línguas estrangeiras eram indispensáveis para os jovens que, no futuro, comandariam os negócios familiares e assumiriam funções na administração pública ou atuariam como profissionais liberais. (ASSUNÇÃO, 2012, p. 18).
}

A troca de experiências, de conhecimentos e de culturas com outros povos possibilitavam uma formação bastante ampla do indivíduo. Fratucci (2008, p. 33) acrescenta que “[...] a viagem exercia papel fundamental para o acúmulo de conhecimento dos jovens e no desenvolvimento de sua percepção de mundo, 
semelhante ao que hoje se conhecemos como viagem de intercâmbio [...]". Argumenta o autor que isso possibilitava uma abertura do ângulo de visão de mundo da pessoa, que seria mais limitado se ficasse circunscrito ao país ou à região onde vivia. Esperava-se que, dessa forma, o diferente seria compreendido e o aprendizado, mais enriquecedor, menos fechado em si. Os aspectos culturais de um determinado povo, cidade ou lugar eram os mais valorizados. Corroborando isso, entende-se a seguinte transcrição de Assunção (2012, p. 19-20):

As viagens passaram a ser componentes culturais importantes na formação intelectual de jovens universitários nos séculos XVIII e XIX. A viagem de estudo tornou-se comum, tendo como destino os grandes centros culturais da Europa. Os jovens visitavam museus, teatros, bibliotecas, sítios arqueológicos, universidades, além de usufruírem de uma interação e experiência cultural única. Rapidamente, as práticas turísticas se diversificavam entre a aristocracia que dispunha de tempo [e dinheiro] para viajar. Os relatos de viagem e a divulgação de locais com belezas culturais e naturais estimularam os deslocamentos. (ASSUNÇÃO, 2012, p. 19-20).

No mesmo período, Fratucci (2008) destaca que, no século XVII, na Inglaterra, as termas já eram bastante conhecidas e frequentadas e que, no início, a procura por estes lugares era devido aos seus poderes curativos, mas, com o tempo, passou a ser também pelo lazer. $\mathrm{O}$ banho em termas era uma prática frequente ainda na Antiguidade, nos impérios Grego e Romano, mas foi um costume que deixou de ser praticado por um longo tempo e então retomado.

É oportuno destacar que os balneários termais ou marítimos contribuíram sobremaneira para uma mudança na forma de percepção dos viajantes para os locais visitados. Além disso, a retomada do hábito do banho de mar vai refuncionalizar diversos trechos do litoral europeu, principalmente da Inglaterra e do sul da França, a partir de um dos mais antigos processos de turistificação do mundo ocidental. (FRATUCCI, 2008, p. 34).

É unânime a ideia que a nova valorização do litoral foi um fator importante para o surgimento do turismo. Assim, compreender como isto ocorreu se torna fundamental pois, como informa Fratucci (2008), no princípio do século XVIII as praias causavam repulsa na sociedade. Meio século mais tarde já eram bastante valorizadas e admiradas, servindo também para os frequentadores e espectadores como mirantes de contemplação. O autor também explica que não se sabe ao certo como passou a se acreditar que os banhos de mar tinham propriedades de cura, mas no século XVIII se 
tornou uma prática comum frequentar balneários na Grã-Bretanha por recomendação médica. No início essa prática, portanto, era por saúde e não como lazer. Com um amplo litoral, muitas cidades se desenvolveram neste país devido aos seus balneários, principalmente no século XIX. A melhoria dos meios de transportes, especialmente as ferrovias, associada com o aumento de renda da população, a diminuição da jornada de trabalho e a conquista das férias remuneradas fez com os balneários se tornassem o paraíso de férias para os britânicos. $\mathrm{O}$ grande sucesso desse atrativo turístico perdurou até a primeira metade do século XX no país. O litoral britânico era satisfatório como atrativo turístico para grande parte da população pelo menos por esse período. Em outros países da Europa, como França e Espanha, os atrativos do litoral do Mar Mediterrâneo passaram a ser frequentados, primeiramente pela aristocracia desse continente, em meados do século XIX. Ainda no século XVIII, com a Revolução Industrial, a burguesia inglesa, detentora dos meios de produção passou também a viajar no próprio país e para outros países do continente europeu, principalmente em busca de novas descobertas de avanços para a produção industrial.

Para Trigo (1998), a burguesia inglesa se consolidou com o enriquecimento da Revolução Industrial a partir da metade do século XIX, e tinha, dessa forma, dinheiro e tempo disponível para viajar pela Europa. Além de uma burguesia industrial, surgiu paralelamente uma burguesia comercial. Este autor considera que esse é o marco inicial do turismo moderno no mundo, pois uma nova classe emergente passa a ter condições financeiras para viagens na Europa e essa prática deixa de ser exclusiva da aristocracia inglesa (mas ainda elitizada). Já as viagens domésticas eram acessíveis a um maior número de pessoas na Inglaterra no século XVIII. As estradas inglesas tiveram franco melhoramento. As diligências, que a princípio foram utilizadas com o propósito de entregas postais, passaram também a transportar pessoas civis e militares.

Na síntese do processo feita por este autor, informa que no século XIX surgiram as ferrovias, consequência da Revolução Industrial, permitindo a ligação entre as principais cidades britânicas. Isso ampliou ainda mais o transporte de pessoas e mercadorias pelo Reino Unido. Foi ampliado consideravelmente o número de funcionários públicos, de profissionais autônomos e comerciantes. Profissionais dessas categorias tinham poder aquisitivo para consumir uma variedade de produtos e serviços, dentre os quais as viagens. 
Outra consequência da Revolução Industrial foi o aceleramento da urbanização na Grã-Bretanha. O ar poluído e a paisagem cinza das cidades industriais sem dúvida alguma não era o ideal pretendido por seus moradores. Dessa forma, a natureza passou a ser mais valorizada. $\mathrm{O}$ desejo de consumo da população passou a serem as viagens para as montanhas e para o litoral. Assim os trabalhadores fugiam do cotidiano estressante e monótono das longas jornadas dentro das fábricas. Depois da Inglaterra, as ferrovias foram construídas em outros países da Europa Ocidental e Estados Unidos. Processos importantes também foram as melhorias dos tipos de locomotivas para o transporte de pessoas (TRIGO, 1998).

Nas informações compiladas por Pires (2002), no ano de 1860 surge nos Estados Unidos o coche salon, inventado por George Pullman e isso permitiu que as viagens longas na América do Norte fossem mais confortáveis aos passageiros. Esse modelo foi aprimorado pela Companhia Internacional Wagon-Lits na Europa na década seguinte. Foram realizados ajustes para que esses tipos de vagões fossem utilizados em trens na trajetória entre Paris e Istambul, capital da Turquia (antiga Constantinopla), passando também por Viena, capital austríaca. Os vagões do tipo coche salon eram espaçosos, com assentos mais amplos que o tradicional, com mesas e abajures fazendo parte do conjunto, permitindo ao passageiro descansar tranquilamente e fazer as refeições durante a viagem. Parte do piso era coberto por tapetes, além de quadros para decorar o ambiente. Os coche salon mais sofisticados possuíam até mesmo camas para os usuários. Se não fosse o movimento do trem, o passageiro se sentiria em um restaurante ou numa sala de estar. Também nos Estados Unidos surgiu outro importante meio de transporte:

\footnotetext{
Os recursos inventados pelos americanos, de forma a fazerem do veleiro um rápido meio de transporte, culminaram na fabricação do clipper, o rei dos veleiros, com o comprimento seis a oito vezes maior que a largura e com número maior de mastros. Embora de manejo delicado, era capaz de vencer o Atlântico, de Leste a Oeste em 11 dias, mas na volta fazia o percurso em 40. Atingia, em 1855, a velocidade aproximada de 16 nós (33 quilômetros por hora). Embora para nós possa parecer de uma lentidão inconcebível, o vapor, que representava a grande novidade náutica, só ultrapassaria essa velocidade em 1880. Em 1850, o Clipper transportava 10 milhões de toneladas, contra mil no vapor. (PIRES, 2002, p. 11-12).
}

Bringhenti (2007) também reforça que os avanços dos meios de transportes marítimos foram importantes para o desenvolvimento do turismo, principalmente nos 
Estados Unidos e Europa no século XIX. Dessa forma, se tornou possível as viagens entre os dois lados do Atlântico setentrional de forma mais eficiente.

\begin{abstract}
Concomitantemente com a rápida expansão das ferrovias na Europa e Estados Unidos, as companhias marítimas impulsionavam com vigor as viagens intercontinentais no hemisfério norte, acarretando inovações no mercado das viagens com respeito à segurança, regularidade, conforto, rapidez e economia, condicionando esses progressos ao desenvolvimento de outros serviços vinculados à atividade, como a hotelaria e os serviços de alimentos e bebidas, destinados aos viajantes. Toda essa inovação possuía um forte aliado: a comunicação. (BRINGHENTI, 2007, p. 28-29).
\end{abstract}

Outro fato importante ocorrido neste país foi que "[...] em 1824, funda-se nos Estados Unidos, Atlantic City [FIGURAS 1 e 2], o primeiro centro turístico de férias e praia das Américas, localizada no estado de Nova Jersey e ponto terminal da Companhia Camden and Atlantic Railroad" (FRATUCCI, 2008, p. 35). As figuras a seguir servem como ilustração do processo de modernização da infraestrutura turística.



"É o tempo do romantismo, uma época na qual se glorificou a natureza e a paisagem, algo que contribuiu decisivamente para o desenvolvimento do turismo" (PÉREZ, 2009, p. 18). Assim, nesse período a Europa passa por uma transformação na literatura.

Um elemento importante na invenção do turismo moderno foi o papel dos escritores e publicistas, que contribuíram para a criação de uma mentalidade colectiva na procura do estranho e do desconhecido. Do mesmo modo estes escritores participaram na criação das ideias românticas de reencontro com a natureza e a história, as águas, o mar e o património cultural. (PÉREZ, 2009, p. 17-18). 
O primeiro a organizar viagens, segundo informações de Bringhenti (2007, p. 28) foi "[...] Bernardo de Abreu - [que] fundou a Agência Abreu, em 1840, em Portugal, comercializava passagens de trem e de navio, inclusive para a América do Sul".

Amaral Junior (2008) também destaca o pioneirismo de Bernardo de Abreu em sua tese. Mas para autores como Pires, o grande nome do turismo moderno foi Thomas Cook, adquirindo relevância a partir de 1841 .

\begin{abstract}
Este inglês, ao que parece, começou suas atividades de uma forma bastante curiosa. Missionário e agente de uma Associação Batista, para assegurar o êxito de um congresso antialcoólico em Leicester, arrendou um trem para transportar 570 pessoas em uma viagem de 22 milhas entre Leicester e Loughborough. Embora não pretendesse nenhum benefício financeiro com esta primeira experiência de viagem coletiva organizada, cedo percebeu seu potencial econômico, pois em 1845 iniciou suas atividades em tempo integral como organizador de excursões, preparando nesse ano, uma excursão de Leicester ao porto de Liverpool, cuja novidade era um Handbook of the trip, que constituiu [...] o primeiro itinerário descritivo de viagem de forma profissional, especialmente para o uso dos turistas. (PIRES, 2002, p. 17-18).
\end{abstract}

Informa ainda que, conseguindo grande sucesso e crescimento, na década seguinte Thomas Cook ampliou suas atividades em cidades de outros países da Europa como na França, Bélgica, Alemanha, Suíça e Itália e posteriormente também no outro lado do Atlântico, notadamente nos Estados Unidos.

Em Londres, Thomas Cook organizou as primeiras viagens e criou o que ficaria conhecido como agências de viagens. A abertura do canal de Suez, em 1869, permitiu um acesso mais rápido ao Extremo Oriente, dinamizando a atividade marítima. Naqueles idos, têm início os luxuosos cruzeiros realizados pelas classes sociais mais favorecidas, marco de ostentação e poder. A Europa, no final do século XIX, fazia o seu avanço pela África e Ásia, a fim de atender os desejos imperialistas e econômicos dos grandes grupos, movimento que não tardaria a ter consequências nefastas no século seguinte. (ASSUNÇÃ̃O, 2012, p. 21).

Pires (2002) destaca também que este inglês organizou a primeira volta ao mundo, formada por um conjunto de nove aventureiros e que esta viagem durou mais de sete meses e foram publicadas as crônicas no jornal londrino Times. "Quando Thomas Cook morreu, em 1892, a Agência de Viagens Cook and Son era a mais importante do mundo. Sua importância, entretanto, está em ter descortinado um novo caminho, como pioneiro que foi” (PIRES, 2002, p. 19-20). As contribuições de Thomas Cook 
provocaram uma evolução no setor do turismo, repercutindo até nos dias atuais, já que as agências de viagens estão entre os principais agentes do setor.

Entretanto, segundo Pires (2002), nesta mesma época em que surgiu a Agência de Viagens Cook and Son, surgiu também nos Estados Unidos a American Express Company, fundada por Henry Wells. Estas duas agências, juntamente com a portuguesa Agência Abreu continuaram funcionando neste segmento turístico. Nas últimas décadas do século XIX passou a se destacar um nome conhecido na história dos hotéis, César Ritz. Sua carreira se iniciou em um importante hotel na Suíça, frequentado pela alta classe aristocrática europeia. Primeiramente foi diretor e posteriormente proprietário de hotéis. César Ritz se tornou mundialmente conhecido, pois provocou uma revolução no ramo “[...] introduzindo serviços até então pouco comuns nos hotéis. A grande novidade ficou por conta da instalação de quartos de banho em todos os apartamentos, com banheiras de mármores e paredes cobertas de azulejos.” (PIRES, 2002, p. 22).

Por volta do final do século [XIX], Ritz chegou a dirigir uma dezena de hotéis, simultaneamente, todos luxuosos e frequentados pela nata da elite europeia e americana, tais como o Grande Hotel de Roma, em 1893, o Hotel Ritz de Paris, em 1898, o hotel Carlton de Londres, em 1899. (PIRES, 2002, p. 21).

Comenta Pires (2002) que essa revolução hoteleira provocada por César Ritz só foi possível associada com a evolução do sistema de transporte no século XIX. A ferrovia permitiu ao turista se locomover e chegar ao destino turístico desejado.

Com o movimento proporcionado pelas ferrovias, a atividade conheceu um desenvolvimento antes sem precedentes. Procurou-se então, adaptá-la ao gosto de uma clientela exigente. Os hotéis, aos poucos, começaram a superar, em conforto, os grandes palácios. O refinamento entra em tudo. Era pouco frequente, por essa época, encontrar nas capitais europeias banhos nos domicílios. Bastou pouco tempo para que os hotéis de luxo tivessem água e banheiro em todos os quartos. Mais tarde, o telefone e outros elementos de conforto surgiram para agradar e tornar mais cômoda a vida de quem pagasse bem. (PIRES, 2002, p. 21).

Outro tipo de entretenimento para a aristocracia e burguesia europeias e que passou a acompanhar alguns grandes hotéis foram os cassinos, como o de Monte Carlo, no Principado de Mônaco (TRIGO, 1998).

Brito (2010) narra a atividade do turismo em Portugal, principalmente a partir do século XIX, acompanhando a evolução dessa atividade no continente europeu. Discorre 
que um bairro de Lisboa, chamado de Monte Estoril, foi urbanizado no final do século XIX especialmente para receber turistas em suas praias. Ao norte do país, na cidade do Porto, uma estância foi construída na década de 1870, próxima a uma ferrovia. Neste caso tudo era administrado pela comunidade, inclusive funções que são do poder público como policiamento e serviço de cartório. Também no norte de Portugal foram construídas as termas em Vidago na década de 1870. Também próximo, as Águas Salgadas passaram a ser muito conhecidas e frequentadas por turistas europeus. "O conjunto de Vidago e Pedras Salgadas é dos mais antigos e mais importantes do País." (BRITO, 2010, p. 19) Essa região de Portugal é famosa por suas águas termais.

$\mathrm{O}$ princípio do século $\mathrm{XX}$ foi um período em que ocorreram grandes transformações relacionadas a viagens e turismo no Ocidente. Diversos foram os fatores interligados que permitiram que essa sucessão de fatos ocorresse.

\begin{abstract}
As primeiras décadas do século $\mathrm{XX}$, conhecidas como Belle Époque, provocaram profundas alterações no cenário econômico, social e político mundial. As grandes descobertas como o telégrafo e o telefone, a expansão da rede de rodovias e ferrovias e o desenvolvimento industrial dos Estados Unidos trouxeram consigo novos conceitos de vida e uma maior liberalização das sociedades. (FRATUCCI, 2008, p. 38-39).
\end{abstract}

Outro aspecto significativo, de acordo com Bringhenti (2007), foi a invenção do automóvel por Henry Ford em 1908 e a sua produção em grande escala nos Estados Unidos, que provocou alterações significativas na prática do turismo individual ou familiar. Esse veículo de transporte se tornou de fácil acesso a uma camada significativa da população estadunidense, tornando as viagens um hábito bastante comum. Ainda segundo Bringhenti (2007), isso forçou também grandes investimentos em infraestruturas rodoviárias para que os automóveis pudessem trafegar pelo imenso território desse país. Urry (2001) também destaca a importância do automóvel no aumento de viagens dos britânicos no período entre guerras.

De acordo com Fratucci (2008), nas primeiras décadas do século XX os principais atrativos turísticos eram os balneários britânicos, as estâncias nas montanhas suíças e o litoral do Mediterrâneo, notadamente a Riviera Italiana e Francesa. O desenvolvimento do transporte aéreo também foi importante nesse período. Em 1918 foi criada na Alemanha a Deutsche Lufthansa, que continua atuando no mercado de 
aviação, inclusive com rotas para o Brasil. Em 1926 foi fundada nos Estados Unidos a Varney Airlines.

Amaral Junior (2008) salienta outros acontecimentos importantes na história do turismo no início do século XX como a utilização do passaporte, adotado primeiramente na Inglaterra, como forma de controle de fluxo de turistas internacionais, em 1915. No ano de 1929 inicia no aeroporto de Amsterdã, capital holandesa, o comércio de mercadorias livre de impostos, chamadas de Duty Free. Pouco tempo depois da invenção e produção do automóvel, foi inventado nos Estados Unidos outro meio de transporte coletivo, em 1921, o ônibus. Consequentemente sua utilização aumentou o turismo utilizando as rodovias. Esses veículos e os serviços a eles relacionados foram aprimorados também ao longo do tempo.

Ainda na década de 1920 “[...] o continente americano também participou com destinos consagrados pelos viajantes que incluíam: Miami Beach (Estados Unidos), Acapulco (México), Bariloche (Argentina) e Punta Del Este (Uruguai)" (BRINGHENTI, 2007, p. 32).

Na Segunda Guerra Mundial a Europa praticamente foi destruída e precisava se reerguer. Assim, “[...] os países europeus buscaram novas formas de financiar as suas reconstruções e o turismo ganhou lugar de destaque como estratégia de desenvolvimento rápido e estimulador de entrada de moedas estrangeiras" (FRATUCCI, 2008, p. 39). Com o auxílio financeiro dos Estados Unidos, os países da Europa Ocidental tiveram seus territórios reconstruídos. Nas décadas que se sucederam houve uma grande expansão industrial e econômica. Juntamente com a estabilidade sociopolítica, o momento era muito favorável também para a recuperação da atividade do turismo.

Segundo informações de Trigo (1998), as tecnologias utilizadas na Segunda Guerra foram utilizadas posteriormente nos transportes aéreos e marítimos comerciais. Essas inovações tiveram grandes impactos no setor turístico.

Depois da Segunda Guerra Mundial e durante mais de meio século, a Europa conhece um período de paz e prosperidade. "Europa da Abundância" é uma designação datada dos anos 60, quando tudo parece possível. Mesmo quando surgem as primeiras dúvidas sobre o futuro, o reforço da União Europeia e a queda do Muro de Berlim alimentam o sonho. (BRITO, 2010, p. 21). 
Na década de 1970 são fabricados aviões do modelo Jumbo 747, da Boing, que tinham capacidade de transportar 400 indivíduos a uma velocidade próxima de 1000 quilômetros por hora, com autonomia de voo de 15 horas sem necessidade de fazer escalas (AMARAL JUNIOR, 2008). A partir desta década o turismo passa para uma nova fase.

Sob a influência dos movimentos ecologistas surgidos na década de 70 e em consonância com as transformações sociais promovidas na década de 80, a atividade turística inaugurou uma fase de transição que culminará no que alguns autores [...] chamam de "pós-turismo" ou, simplesmente, o turismo na pós-modernidade. (BURSZTYN, 2005, p. 17).

E, na década de 1990, as mudanças econômicas de forma generalizada no cenário mundial também afetaram o turismo. Este setor teve que se adequar a uma nova realidade como a flexibilidade no processo de produção, além do capital financeiro, que passou a ser internacionalizado. O fluxo turístico, que estava concentrado na rota América do Norte e Europa, passa a ser importante também em países do Leste Europeu e na China, que tiveram abertura de suas economias. Os países do Sudeste Asiático também se tornaram importantes destinos internacionais de turistas (BURSZTYN, 2005).

O turismo praticado atualmente é muito diferente de tempos anteriores. "Isto não ocorreu aleatoriamente, sempre esteve intrinsecamente ligado com as características da sociedade e o contexto econômico, social, político e cultural que o envolvia" (OLIVEIRA, 2006, p. 21). A forma que se enxerga os horários de folga do trabalho e de outros compromissos também mudou com o passar do tempo.

\footnotetext{
[...] hoje não há tempo totalmente livre e sim livre de obrigações específicas do tempo de trabalho. Não há tempo livre e, sim, tempo a ser consumido, preenchido de forma eficaz e produtiva. Atualmente as pessoas viajam, não porque têm tempo livre e sim porque viajar é necessário, pois permite o acesso à cultura, à informação, à atualização, ao lazer, além de significar status. (OLIVEIRA, 2006, p. 21).
}

Assim, conclui-se, com Oliveira (2006) que o turismo passou a ser uma prática, além de desejada, quase obrigatória para significativos segmentos da sociedade, tornando-se um item de consumo e de prestígio social, principalmente as viagens 
internacionais. O turismo se transforma em algo muito além de uma atividade de lazer, um elemento fundamental de valor agregado na sociedade do conhecimento.

\section{CONCLUSÃO}

Praticar o turismo, além de ser uma forma de lazer, pode ser adquirir cultura (erudita e popular) e conhecimento com as viagens e experiências. Significa continuar conectado com os acontecimentos e fatos. $\mathrm{Na}$ era das imagens e da internet, pode-se enviar fotografias digitais dos destinos visitados em tempo real nas redes sociais através de diversos aparelhos eletrônicos como telefone celulares, tablets e notebooks, entre outros, ao mesmo tempo em que é possível visualizar o que os amigos, colegas e conhecidos postaram. Pode-se dizer que o turismo se tornou quase obrigatório.

A revisão bibliográfica esclareceu que o turismo passou por uma longa evolução ao longo do tempo, desde os deslocamentos realizados por pequenos grupos de pessoas utilizando simples meios de transportes até a diversidade e rapidez do mundo vigente. Os atrativos turísticos valorizados também mudaram e continuam mudando. Uma prática possível apenas a uma camada elitizada em boa parte do curso da história passou a ser acessível a um número muito maior de pessoas no cenário mundial, principalmente neste século XXI, e em contínua expansão.

O turismo passou a ser um dos mais importantes setores econômicos na sociedade contemporânea e a principal atividade econômica de vários países. Após a pesquisa, compreendeu-se que, para isso, mudanças sociais foram necessárias, como, por exemplo: o desenvolvimento de rotas marítimas e terrestres, ainda na Grécia Antiga e no Império Romano; as peregrinações desde o início do Cristianismo; a recepção dos viajantes nos mosteiros, tabernas e, depois, pousadas; o avanço técnico exigido e que permitiu as Grandes Navegações; a literatura de viagens; os grand tours; o retorno do hábito social das termas; a difusão da ideia que o banho de mar tinha poderes curativos; a Revolução Industrial e o enriquecimento da burguesia; as diligências, as ferrovias e o avanço na engenharia náutica; a criação das agências de viagens; a mudança na concepção dos hotéis; a organização de territórios especificamente para o turismo; a expansão da rede de comunicação; a invenção do automóvel; o transporte aéreo e seu 
desenvolvimento técnico; a ideia da atividade turística como possibilidade para melhorar a economia de alguns países e as mudanças na legislação trabalhista. Após estas breves "pinceladas" que descortinam a complexidade da história do turismo, sabendo que a velocidade das mudanças técnicas que se está vivenciando é sem precedentes, a mente curiosa passa a pensar o futuro próximo e em como estas mudanças se refletirão no turismo. Então, a importância de compreender o processo histórico pode ser exatamente esta: entender o mundo social e o espaço geográfico em interação e contínuo movimento, portanto apreender o turismo em sua incessante transformação.

\section{REFERÊNCIAS}

AMARAL JUNIOR, J. B. C. O Turismo na periferia do capitalismo: A revelação de um cartão postal. 650 f. Tese (Doutorado em Ciências Sociais). Pontifícia Universidade Católica de São Paulo. São Paulo, 2008. Disponível em: <http://www.sapientia.pucsp.br/tde_busca/arquivo.php?codArquivo=6761>. Acesso em: 10/03/2013.

ASSUNÇÃO, P. de. História do turismo no Brasil entre os séculos XVI e XX: Viagens, espaço e cultura. Barueri: Manole, 2012.

BRINGHENTI, A. A. Turismo internacional no Brasil: 1995-2002 - O papel do Estado na história, conquistas, retrocessos. 228 f. Dissertação (Mestrado em História). Faculdade de Filosofia e Ciências Humanas. Pontifícia Universidade Católica do Rio Grande do Sul. Porto Alegre, 2007. Disponível em: <http://repositorio.pucrs.br/dspace/bitstream/10923/3748/1/000399686-Texto\%2b Completo-0.pdf>. Acesso em: 11/12/2013.

BRITO, S. P. Imobiliária do lazer e turismo residencial. Porto: SPI, 2010. Disponível em: 〈http://web.spi.pt/turismo/Manuais/Manual_V.pdf >. Acesso em: 18/02/2014.

BURSZTYN, I. Políticas públicas de turismo visando a inclusão social. $110 \mathrm{f}$. Dissertação (Mestrado em Engenharia de Produção). Instituto Alberto Luiz Coimbra de Pós-Graduação e Pesquisa de Engenharia. Universidade Federal do Rio de Janeiro. Rio de Janeiro, 2005. Disponível em: <http://www.dadosefatos.turismo.gov. br/export/sites/default/dadosefatos/espaco_academico/ dissertacoes_teses/downloads_dissertacoes_teses/20110629-Ivan_Bursztyn-43.pdf >. Acesso em: 10/12/2013.

FRATUCCI, A. C. A dimensão espacial nas políticas públicas brasileiras de turismo: As políticas das redes regionais de turismo. $309 \mathrm{f}$. Tese (Doutorado em 
Geografia). Departamento de Geografia. Universidade Federal Fluminense. Niterói, 2008. Disponível em: <http://www.bdtd.ndc.uff.br/tde_arquivos/26/TDE-2009-0528T131249Z-2005/Publico/Agnaldo\%20Fractucci-Tese.pdf>. Acesso em: 12/10/2012.

JOHNSON, N. Tourist visit Atlantic City and its beach. 2002. 1 fotografia, black and white. Disponível em: <http://3.bp.blogspot.com/-E_y2LHq6-g4/UDOqiu08b5I/ AAAAAAAAK8s/evfUcs6-I34/s1600/Bathers,\%2BAtlantic\%2BCity,\%2BNew\%2B Jersey,\%2B1905-1920.jpg>. Acesso em: 15/02/2014.

MASS, M. Boardwalk Wine Promenade attendees will enjoy gorgeous views as they visit various wine stations. 2013. 1 fotografia, color. Disponível em: $<$ http://s3.amazonaws.com/cmi-niche/assets/pictures/25017/content_Atlantic-CitySkyline.jpg?1367530060>. Acesso em: 20/4/2014.

OLIVEIRA, F. M. de. Espaço, lugar, identidade e urbanização: Conceitos geográficos na abordagem do turismo. 124 f. Dissertação (Mestrado em Geografia). Instituto de Geociências. Universidade Federal de Minas Gerais. Belo Horizonte, 2006. Disponível em: <http://www.bibliotecadigital.ufmg.br/dspace/bitstream/ handle/1843/MPBB-6VRH3N/flavia_moura_de_oliveira.pdf?sequence=1 >. Acesso em: $11 / 12 / 2013$.

PÉREZ, X. P. Turismo cultural: Uma visão antropológica. El Sauzal (Tenerife, Espanha): ACA y PASOS, 2009. Disponível em: <http://www.pasosonline.org/ Publicados/pasosoedita/PSEdita2.pdf >. Acesso em: 28/11/2013.

PIRES, M. J. Raízes do Turismo no Brasil. 2. ed. Barueri: Manole, 2002.

TRIGO, L. G. G. Turismo básico. 2. ed. São Paulo: Senac, 1998.

URRY, J. O olhar do turista: Lazer e viagens nas sociedades contemporâneas. São Paulo: Studio Nobel/SESC, 2001.

Recebido em: 19-09-2015.

Aprovado em: 19-10-2015. 